\title{
PERCEPÇÃO DE QUALIDADE DA CARNE BOVINA COM MARCA NO SUL DO BRASIL
}

\author{
QUALITY PERCEPTION OF BEEF WITH BRAND IN THE SOUTH OF BRAZIL
}

\author{
Maysonnave, G.S. ${ }^{2}$; Vaz, F.N. ${ }^{1 *}$; Pascoal, L.L.; Pacheco, P.S.; Mello, R. de O.; \\ Machado, G.K. e Nardino, T.A.C.
}

\begin{abstract}
${ }^{1}$ Departamento de Zootecnia. Universidade Federal de Santa Maria. Santa Maria, RS. Brasil. *fabianonunesvaz@gmail.com; ²greicysm@gmail.com
\end{abstract}

\section{PalaVRas ChaVe ADICIONAIS}

Decisão de compra. Diferenciação da carne bovina. Filière. Informação na cadeia produtiva. Supermercados. Tomada de decisão.

\section{RESUMO}

O objetivo deste estudo foi analisar a qualidade percebida por diferentes agentes da cadeia produtiva da carne bovina com marcas no Estado do Rio Grande do Sul e o grau de uniformidade entre as diferentes percepções. Os dados foram obtidos por meio de uma pesquisa exploratória descritiva, utilizando-se como instrumento de coleta de dados um questionário-base estruturado com seis questões que abrangiam sete níveis da cadeia de produção: i) consumidores, ii) açougueiros, iii) gerentes de perecíveis e iv) gerentes gerais dos supermercados, v) gerentes de vendas de carne e vi) gerentes de compra de gado da indústria frigorífica e vii) produtores rurais. Os resultados mostraram que mesmo numa cadeia de carne de qualidade com valor agregado, o fator de maior influência na compra da carne pelo consumidor foi o preço e a fonte de informações mais importante aos consumidores ainda é o açougueiro. Das questões pesquisadas, o maior coeficiente de variação foi observado nas questões quem pode dar informações sobre qualidade de carne para os consumidores? e em sua opinião, a raça garante melhor qualidade à carne?, mostrando baixa concordância entre os agentes de carne (60 $\%)$. Por outro lado, a maior uniformidade (30\%) de respostas foi observada nas questões marque a importância de 1 a 5 dos fatores de maior influência na hora da compra de carne e em ordem, quais são as informações mais importantes como indicadores de qualidade da carne?. Concluiu-se que os diferentes agentes da cadeia de produção

\section{AdDITIONAL KEYWORDS}

Decision-making. Filière. Meat differentiation. Purchase decision. Supermarkets. Supply chain information.

possuem entendimento relativamente uniforme a respeito da qualidade de carne entre si e possuem boa percepção das preferências dos consumidores.

\section{SUMMARY}

The objective of this study was to analyze the quality perceived by different actors in beef marks chain production at Rio Grande do Sul state. The data were obtained through a descriptive exploratory research, using as an instrument of data collection standards a based structured questionnaire with six questions covering seven levels of the beef market chain: i) consumers, ii) butchers, iii) perishable managers and iv) supermarket general managers, v) sales managers of meat and vi) cattle purchase managers and vii) farmers. The results showed that the most important source of information for consumers is still the butcher. From researched questions the highest coefficient of variation was observed in the questions who can inform about meat quality to consumers? and in your opinion, does the breed guarantee meat quality?, showing low agreement among the meat agents $(60 \%)$. On the other hand, the higher uniformity $(30 \%)$ of responses was observed in the questions mark the importance from 1 to 5 the attributes of higher influence at meat purchase moment and in order, what is the more important information as indicators of quality meat?. It was concluded that 
the different actors of the production chain have relatively similar understanding about the quality of meat each other and have good understanding of consumer preferences.

\section{INTRODUÇÃO}

Embora sas exportações sejam representativas no mercado internacional, estima-se que $85 \%$ da nossa produção seja consumida internamente. A melhoria do poder aquisitivo da população brasileira neste início de século impulsionou o aumento do consumo per capita e a busca por qualidade no produto carne bovina (Batalha e Buainain, 2007).

Esse fato é importante se observada a história recente da comercialização de carne bovina, épocas em que o conhecimento sobre os cortes, a origem e o ponto de venda das carnes tinham pouca influência sobre as decisões de compras dos consumidores (Barcellos et al., 2011). Atualmente, sob o rótulo de busca de qualidade, os consumidores se deparam com farta opções de produtos cárneos diferenciados, identificação de cortes, preparos, embalagens, identificação de origem e rotulagens de marcas ligadas aos sistemas de criação e às raças (Champredonde et al., 2014).

A indústria frigorífica e as associações de raças investiram na identificação de cortes de determinadas raças, oriundos de animais com limitação de idade e acabamento padronizado. A motivação para isso é a agregação de valor ao produto, buscando atender ao novo padrão de consumo do mercado interno, que não gostaria mais de arriscar no fator qualidade de carne. No entanto, aos varejistas e até mesmo para algumas pessoas de dentro da indústria frigorífica esses conceitos não parecem claros. Atualmente se discute se a qualidade medida e indicada nos trabalhos de laboratório de carnes é a qualidade buscada pelos consumidores que analisam não só o produto, mas também questões ligadas à embalagem, à conveniência, e saudabilidade. De acordo com Mazzuchetti e Batalha (2004), os fatores preço e renda ainda são importantes na compra da carne bovina, no entanto é crescente a influência de fatores como segurança alimentar, efeito saúde, qualidade, palatabilidade e conveniência. Neste sentido as carnes com marca podem suprir essa demanda em ascensão através da confiabilidade que objetivam demonstrar.

Para completar a situação problema, a integração entre os agentes da cadeia produtiva é baixa, em função de disputas pelas maiores margens de lucro oferecidas no preço de venda agregado que o consumidor paga por esses novos produtos (Brisola e Castro, 2005a). Essas disputas podem gerar falhas ao longo da cadeia e fazer com que chegue ao consumidor final um produto com menor qualidade, ou ainda, um produto que pode não ser exatamente 0 que este desejava, não satisfazendo assim, às suas necessidades. Brisola e Castro (2005b) classificam a sintonia da informação entre os agentes da cadeia produtiva da carne bovina como a pureza da recepção de informações a respeito de qualidade por parte dos agentes, onde a alta sintonia representaria baixo ruído no fluxo de informações.

Por outro lado, a consolidação de uma cadeia de produção de uma carne diferenciada está relacionada ao custo que o processo de certificação agrega ao produto e repassa ao consumidor final, o que muitas vezes pode ocasionar em baixa aceitação do produto oferecido. Schnettler e Sepúlveda (2007) observaram que na cadeia da carne bovina no Chile tem aumentado nos últimos anos, as margens de lucro dos varejistas e atacadistas, ficando a produção rural com as menores margens, o que pode desestabilizar a cadeia de produção primária (Zylberztajn, 2000).

O objetivo deste estudo é analisar a percepção de qualidade dos diferentes agentes da cadeia produtiva da carne bovina com marcas, pesquisando-se duas redes de supermercados de cinco cidades do estado do Rio Grande do Sul, Brasil. 


\section{MÉTODOS DE PESQUISA}

\section{TIPO DE PESQUISA E DEFINIÇÃO DAS AMOSTRAS}

Este estudo foi realizado entre os meses de maio a novembro de 2012, por meio de uma pesquisa exploratória descritiva com sete agentes integrantes da cadeia da carne bovina. Foram coletados dados acerca da percepção de qualidade do produto cárneo com marca em cinco cidades do Estado do Rio Grande do Sul, Brasil. As cidades pesquisadas foram a Capital do Estado (Porto Alegre), três cidades da Região Metropolitana: Canoas, Sapucaia do Sul e Novo Hamburgo, e Santa Maria uma cidade da Região Central do Estado.

Foram estudadas duas redes de supermercados, numa amplitude de quatro grupos mais representativos nas cidades estudadas. Também influenciou na escolha a perceptível diferença de poder aquisitivo entre os freqüentadores, sendo os consumidores da rede $\mathrm{A}$, em média, de maior poder aquisitivo que os consumidores da rede B.

Na sequência foi contatada a empresa frigorífica que comercializava esses produtos com as redes e agendada entrevista com o gerente comercial, responsável pela venda de carnes de marcas e o gerente de compra de gado. Este último agente informou uma listagem e o contato de vinte produtores significativos no fornecimento de lotes de animais que se enquadravam nos programas de carnes de marcas.

Para completar o encadeamento da cadeia de produção, foram procurados os gerentes gerais das redes de supermercados, os quais, além de autorizarem a abordagem aos consumidores e de responderem aos questionários, encaminharam os pesquisadores para os gerentes de perecíveis. Estes últimos responderam aos entrevistadores e os encaminharam aos açougueiros de cada loja.

Por meio das questões se procurou caracterizar o perfil das pessoas entrevistadas no tocante ao gênero, idade, escolaridade, além de questões sobre qualidade e informações referentes aos produtos pesquisados.

\section{Agentes estudados}

Consumidores. Para obter dados dos consumidores, foram entrevistadas 286 pessoas que frequentavam sete grandes lojas de duas grandes redes de supermercados que atuam em Porto Alegre, Região Metropolitana da capital e Santa Maria, cidade do interior do estado.

Agentes ligados aos supermercados. Foram realizadas entrevistas com cada um dos açougueiros que atendiam nas lojas, obtendo-se sete entrevistas. Num segundo momento, foram abordados os gerentes de perecíveis locais das lojas, responsáveis pela análise de venda da carne, reposição e conservação do produto, obtendo-se mais sete questionários preenchidos. Em nível hierárquico mais acima, foram entrevistados os gerentes gerais das redes de supermercados, os quais são responsáveis pelas negociações de preço e mix de produtos para cada rede de supermercados, obtendose assim mais duas entrevistas.

Agentes ligados à indústria frigorífica. Foi entrevistado o gerente comercial da empresa frigorífica, bem como o gerente responsável pela compra de gado da mesma empresa. Na sequência, a partir dos contatos passados pelo responsável pela compra de gado, foram procurados por telefone os vinte fornecedores de gado indicados, aos quais foi explicado o objetivo da pesquisa e encaminhado aos mesmos os questionários por correio eletrônicoobtendo-se retorno de sete formulários preenchidos.

Aplicação dos questionários. O instrumento de coleta de dados foi o documento por meio do qual as questões eram apresentadas aos respondentes e onde eram registradas as respostas e os dados obtidos.

Foi elaborado um questionário-base estruturado com seis questões, aplicadas pessoalmente por entrevistador previamente treinado, exceto aos produtores, cujo 
Tabela I. Caracterização da amostra de consumidores conforme o gênero, idade e grau de escolaridade.(Characteristics of consumers samples by gender, age and educational level).

\begin{tabular}{lcccc}
\hline \multirow{2}{*}{ Característica } & Variável & Número & Frequência & Estado \\
Frequência
\end{tabular}

formulário foi encaminhado por email, devido a dispersão geográfica destes.

Essa base de perguntas foi adequada para que o questionário pudesse ser aplicado nos diferentes agentes da cadeia de produção, com pequenas alterações relacionadas às tomadas de decisão necessárias. Teve-se cuidado para que não ocorresse alteração da investigação a respeito da percepção de qualidade, de forma a poder identificar a sintonia de percepção entre os sete agentes pesquisados.

Análise dos resultadosApós a coleta dos dados, estes foram analisados utilizando o software Microsoft Office Excel 2007®, calculando-se médias, frequência e coeficiente de variação para cada questão. Foram feitas três comparações, conforme descrito nos próximos itens.

Análise entre redes de supermercados. Considerando que as redes $A$ possui direcionamento a um público com maior poder aquisitivo, comparou-se as respostas entre consumidores, açougueiros, gerentes de perecíveis e gerente geral de cada rede. As respostas foram submetidas à análise por Qui-quadrado $\left(X^{2}\right)$ ao nível de $10 \%$ de significância.

Análise entre cidades. Dentro das mesmas redes de supermercados foram comparadas as respostas dos consumidores e dos açougueiros e gerentes de perecíveis que trabalham nas cidades classificadas como Capital (Porto Alegre), Região Metropolitana (Canoas, Novo Hamburgo e Sapucaia do Sul) e interior do estado (Santa Maria).

Análise entre agentes. A análise de sintonia foi realizada comparando as respostas dos diferentes agentes para as mesmas seis questões relacionadas à percepção de qualidade. As respostas possíveis dos questionários estruturados foram transformadas em números para o cálculo do desvio-padrão nas respostas dos agentes, o que permitiu analisar a uniformidade das respostas.

Dessa análise, foram estudados os coeficientes de variação obtidos em cada questão, indicativos do grau de uniformidade de respostas.

\section{RESULTADOSE DISCUSSÃO}

\section{Perfildos consumidores}

Para a caracterização da amostra de consumidores de carne bovina, utilizaram-se as características: gênero, idade e escolaridade (tabela I).

Observa-se que os consumidores do sexo masculino foram mais representativos na amostra, já que 51,33 \% da população do 
Tabela II. Fatores que influenciam na decisão de compra pelo consumidor (\%) nas redes pesquisadas. (Factors influence in the purchase decision by consumers (\%) in networks surveyed).

\begin{tabular}{lccccc}
\hline Rede* & Marca & Embalagem & Preço & Corte & $\begin{array}{c}\text { Experiências } \\
\text { anteriores }\end{array}$ \\
\hline A & 8,7 & 7,9 & 32,5 & 38,9 & 11,9 \\
$B$ & 10,0 & 10,8 & 36,7 & 27,5 & 15,0 \\
Pr $>X^{2}$ & 0,83 & 0,53 & 0,74 & 0,07 & 0,60 \\
\hline
\end{tabular}

*Rede A caracterizada por público com menor poder aquisito que a rede $\mathrm{B}$.

estado é de mulheres. Em relação à idade, 45 $\%$ dos respondentes são da faixa etária 41 a 60 anos, sendo que no estado, essa faixa etária corresponde a $26 \%$ da população. No entanto, desconsiderando os jovens de 0 a 25 anos, que na amostra foram apenas $6 \%$, a faixa etária de 41 a 60 anos representa 43 \% da população do Rio Grande do Sul(IBGE, 2014). A baixa representatividade do público jovem reflete uma pesquisa feita dentro das lojas, onde os respondentes eram apenas os consumidores, não sendo arguidas os adolescentes e crianças acompanhadas de adultos.

\section{COMPARAÇÃO ENTRE REDES DE SUPER- MERCADOS}

Quando os consumidores foram questionados sobre os fatores que influenciam em suas decisões de compra as variáveis preço e corte foram os itens mais citados (tabela II), observando-se diferença $(p<0,10)$ por análise de Qui-quadrado entre as redes A e B, quando a resposta corte foi citada.
Na rede A, o corte teve maior influência na escolha $(p<0,10)$, com $38,9 \%$ das respostas. Pode indicar que as pessoas com maior poder aquisitivo passam a procurar os cortes de sua preferência, valorizando os cortes mais indicados ao seu tipo de consumo e forma de preparo. Esse fato pode ser mais evidente em carnes com marca que disponibilizam ao varejo apenas os cortes mais valorizados, como aqueles destinados a preparo de assados e grelhados.

Quando os consumidores foram questionados sobre a forma de obter informações que mais confiam, as respostas foram bastante similares entre os freqüentadores das duas redes de supermercados, sendo a resposta açougueiro seguido de amigos $e$ familiares as respostas mais citadas (tabela III). Respostas como supermercado e especialistas apresentaram menos de $10 \%$ de frequência.

Questionados sobre as informações que melhor podem ser usadas como indicador de qualidade das carnes bovinas de marca,

Tabela III. Formas de obtenção de informação pelo consumidor (\%) nas redes pesquisadas. (Sources of obtaining information for the consumer (\%) on networks surveyed.

\begin{tabular}{lccccc}
\hline Rede* $^{*}$ & Açougueiro & Embalagem & Amigos e familiares & Especialistas & Supermercado \\
\hline A & 42,9 & 13,5 & 30,2 & 9,5 & 4,0 \\
$\mathrm{~B}$ & 46,7 & 17,5 & 24,2 & 9,2 & 2,5 \\
$\mathrm{Pr}>\mathrm{X}^{2}$ & 0,85 & 0,52 & 0,27 & 0,83 & 0,48 \\
\hline
\end{tabular}

*Rede A caracterizada por público com menor poder aquisito que a rede B. 
Tabela IV. Fonte de informação mais importante como indicador de qualidade da carne nas redes de supermercado pesquisadas (\% dos consumidores). (Most important source of information as an indicator of meat quality in supermarket chains surveyed (\% of consumers)).

\begin{tabular}{lcccccc}
\hline Rede* $^{*} \begin{array}{c}\text { Dados sobre } \\
\text { o animal }\end{array}$ & $\begin{array}{c}\text { Marca da empresa } \\
\text { processadora }\end{array}$ & Resfriamento & $\begin{array}{c}\text { Aspecto do } \\
\text { produto }\end{array}$ & $\begin{array}{c}\text { Aspecto da } \\
\text { embalagem }\end{array}$ & Fiscalização \\
\hline A & 8,7 & 7,1 & 11,1 & 43,7 & 6,30 & 23,0 \\
$\mathrm{~B}$ & 2,5 & 2,5 & 8,3 & 52,5 & 5,80 & 28,3 \\
$\mathrm{Pr}>\mathrm{X}^{2}$ & 0,03 & 0,08 & 0,41 & 0,46 & 0,80 & 0,53 \\
\hline
\end{tabular}

*Rede A caracterizada por público com menor poder aquisito que a rede B.

nas duas redes de supermercados as respostas mais citadas foram aspecto do produto com, na média, quase metade das respostas, seguido dos dados sobre fiscalização (tabela IV).

A pesquisa também questionou os consumidores sobre o quanto mais vale uma carne com algum tipo de selo de qualidade (tabela V). Embora sem diferença estatística entre as redes pesquisadas $(\mathrm{p}>0,10)$, mais da metade dos consumidores da rede $B$ disseram que essas carnes não valem mais que as carnes sem selo de qualidade. Já na rede A, esse percentual foi 35,7\%. Entre os consumidores que valorizam esses produtos, houve distribuição relativamente uniforme entre as respostas $10 \%$ mais (média 20,7\%), $20 \%$ mais (média 15,4\%) e $30 \%$ ou mais (média 20,3\%).

Tabela V. Quanto a mais vale uma carne com algum selo de qualidade (\% dos consumidores). (How much more worth a beef with some quality seal (\% of consumers)).

\begin{tabular}{lcccr}
\hline Rede* $^{*}$ & $\begin{array}{c}\text { Não } \\
\text { vale mais }\end{array}$ & $\begin{array}{l}10 \% \\
\text { mais }\end{array}$ & $\begin{array}{l}20 \% \\
\text { mais }\end{array}$ & $\begin{array}{r}30 \% \\
\text { ou mais }\end{array}$ \\
\hline A & 35,7 & 23,8 & 18,3 & 22,2 \\
B & 51,7 & 17,5 & 12,5 & 18,3 \\
$\mathrm{Pr}>X^{2}$ & 0,10 & 0,21 & 0,19 & 0,40 \\
\hline
\end{tabular}

*Rede A caracterizada por público com menor poder aquisito que a rede $B$.
Vale salientar que na tabela VI que o percentual de consumidores que já provaram carnes com selo ligados às raças bovinas foi semelhante entre as duas redes de supermercados.

A freqüência de respostas nunca provei pode ser considerada alta em função do representativo espaço que essas carnes possuíam nas lojas pesquisadas. Entre as marcas Angus, Pampa e outra raça, se observou maior freqüência de pessoas que já haviam provado carnes com a marca Angus.

\section{FATORES QUE INFLUENCIAM NA DECISÃO DE COMPRAPELOCONSUMIDOR}

A figura 1 mostra que os fatores que influenciam na decisão de compra dos consumidores estão relacionados à corte

Tabela VI. Consumo de carne com o selo ligado a alguma raça bovina (\% dos consumidores). (Meat consumption with the seal attached to any breed of cattle (\% of consumers)).

\begin{tabular}{lcccc}
\hline Rede* & Nunca provei & Angus & Pampa & $\begin{array}{c}\text { Outra } \\
\text { raça }\end{array}$ \\
\hline A & 89,7 & 7,1 & 0,8 & 2,4 \\
$\mathrm{~B}$ & 90,0 & 8,3 & 0,8 & 0,8 \\
$\mathrm{Pr}>\mathrm{X}^{2}$ & 0,74 & 0,82 & 1,00 & 0,32
\end{tabular}

*Rede A caracterizada por público com menor poder aquisito que a rede $B$.

Archivos de zootecnia vol. 63, num. 244, p. 638. 


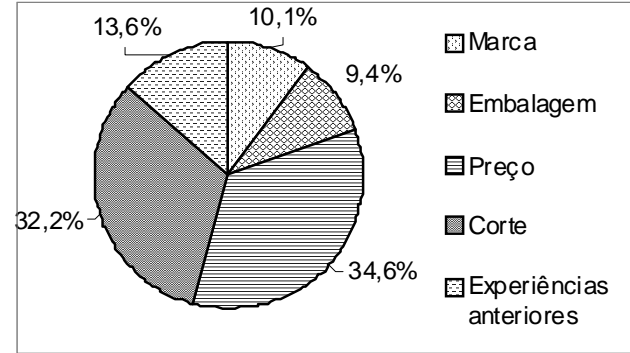

Figura 1. Fatores que influenciam na decisão de compra pelo consumidor independente da rede de supermercado pesquisada. (Factors influence the purchase decision of the consumer independent of the supermarket network surveyed).

(33,3 \%) e o preço (34,6 \%). Essa informação é similar àquela apresentada por Brisola e Castro (2005a) que, ao identificarem os atributos de preferência dos consumidores observaram que 47,6 \% destes buscam preços baixos, sendo que essas diferenças em preço podem alterar a lealdade do consumidor (Souza, 1999).

Os resultados da figura 2 mostram que $44,7 \%$ dos entrevistados confiam na indicação do açougueiro para lhes dar informações sobre qualidade de carne. Essa informação é correspondente a observada por Grunert et al. (2004), quando verificou que o açougueiro tem alto grau de influência

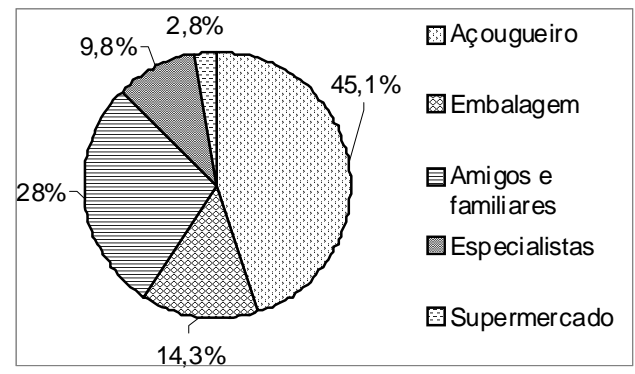

Figura 2. Formas de obtenção de informação pelo consumidor independente da rede de supermercado pesquisada. (Sources of obtaining information by the consumer independent of the supermarket network surveyed). ao fornecer informação sobre a qualidade da carne. Barcellos (2004) também constatou ser o açougueiro o principal agente fornecedor de informações, citado por $36 \%$ dos respondentes, seguido por informações obtidas com amigos e familiares com 20,1 \% das respostas.

Barcellos e Callegaro (2002) comentam que a compra de carne bovina é um processo de tomada de decisão limitada, em virtude das particularidades, tais como baixo envolvimento, pouca busca de informações e avaliação de alternativas. Para os mesmos autores, o consumidor forma crenças sobre o produto, realiza a compra e procede a avaliação baseada no julgamento inicial. Segundo Brisola e Castro (2005a) isso se deve ao baixo nível de conhecimento dos consumidores sobre o produto cárneo e dos fatores que influenciam na sua qualidade. Essa informação pode ser corroborada com o resultado obtido no presente trabalho, onde o açougueiro é uma importante fonte de informação.

A embalagem foi citada por 15,4\% dos entrevistados como fonte de informação. Barcellos e Callegaro (2002)concluíram ser este um agente promissor no sentido de informar o consumidor sobre o produto que está escolhendo. No presente trabalho, verificou-se que a maioria dos consumidores $(47,6 \%)$, considera aspecto do produto como o indicador de qualidade mais importante (figura 3), enquanto a marca de empresa processadora, os dados sobre o animal e o aspecto da embalagem apresentaram frequência entre 5 e $6 \%$.

Souki et al. (2003) citam que a aparência do produto é o terceiro aspecto de maior importância no momento da compra, atrás apenas da higiene e do odor, enquanto os dados sobre o animal (5,7\%) e a marca da empresa processadora (4,9\%) foram os aspectos citados como menos importantes.

Na quarta questão (figura 4) procurouse avaliar o conhecimento e a disposição do consumidor de carne bovina quanto ao selo de qualidade da carne e quantificar o valor 


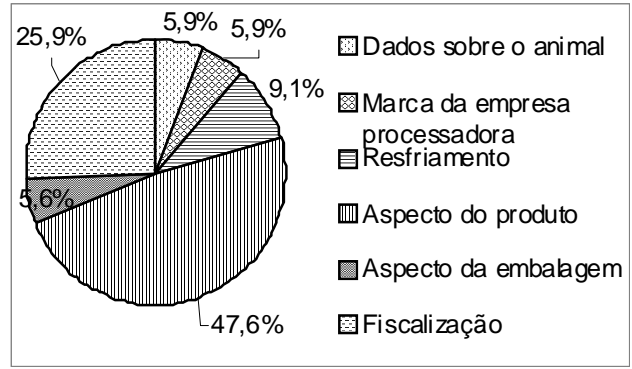

Figura 3. Fonte de informação mais importante como indicador de qualidade da carne independente da rede de supermercado pesquisada. (Most important source of information as an indicator of beef quality independent of the grocery store network surveyed).

que o consumidor estaria disposto a pagar por este processo que envolve a certificação do produto pelas associações de raças. O resultado mostrou que $43,5 \%$ dos consumidores citaram que o selo da raça não vale mais, o restante pagaria entre 10,20 e $30 \%$ ou mais pelo produto. Dos entrevistados na pesquisa de Velho et al. (2009) 17 \% não pagariam mais por carne certificada e $68 \%$ das pessoas estariam dispostas a pagar até $10 \%$ a mais sobre o valor da carne. $\mathrm{Na}$ mesma pesquisa, os autores identificaram que apenas $8 \%$ dos consumidores estariam dispostos a pagar pela certificação racial (Velho et al., 2009). No entanto, Verbeke et al. (2013) observaram que os consumidores

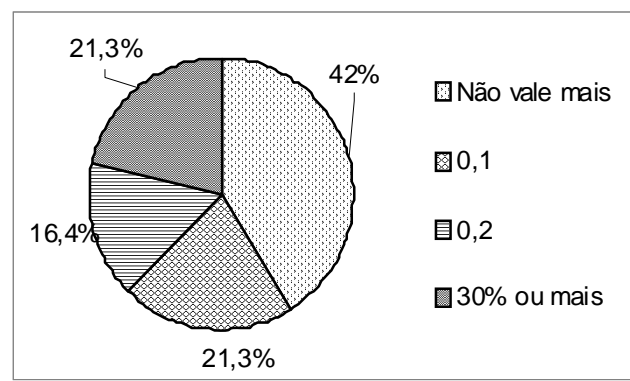

Figura 4. Quanto a mais vale uma carne com algum selo de qualidade?. (How much more worth a beef with some quality seal?). muçulmanos belgas estavam dispostos a premiar, em média, $19 \%$ a mais pela carne Halal. Porém, os autores frisam que as respostas obtidas mostram uma valorização subjetiva que talvez não se traduza em real intenção de pagamento, o que também pode ter ocorrido neste trabalho.

O selo tem como objetivo assegurar a qualidade da carne em todas as etapas de produção, ou seja, da fazenda a gôndola do supermercado. Segundo os princípios das carnes Angus e Pampa, a certificação desses produtos atesta também uma garantia relacionada a uma idade máxima de abate (quatro dentes na Carne Angus e seis dentes na Carne Pampa), a qual seria um indicativo de maciez ao produto oriundo de animais jovens (Vaz et al., 2002). Na presente pesquisa, ao questionar os consumidores quanto ao consumo de carne ligada a algum selo de raça, 87,8 \% dos consumidores disseram nunca ter provado o produto (figura 5). Esse resultado mostra que as carnes com selo de raça ainda são produtos consumidos por determinados nichos de mercado. Estudando a carne certificada na Espanha, Angulo e Gil (2007) citam que a restrição orçamentária dos consumidores limita a premiação das carnes certificadas por meio do pagamento de maior preço. Pesquisando carne com indicação geográfica, Brandão et al. (2012) observaram que $65,4 \%$ dos consumidores entrevistados

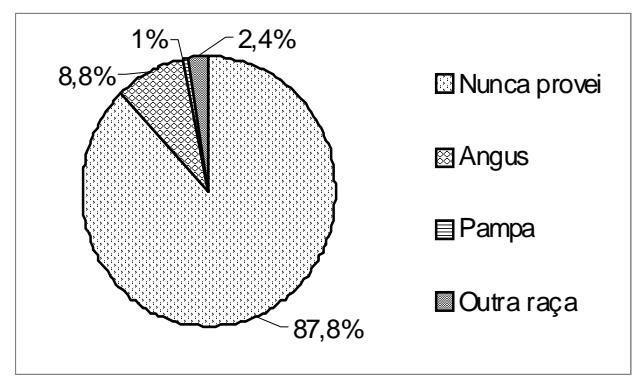

Figura 5. Consumo de carne com o selo ligado a alguma raça. (Meat consumption with the breed seal attached). 


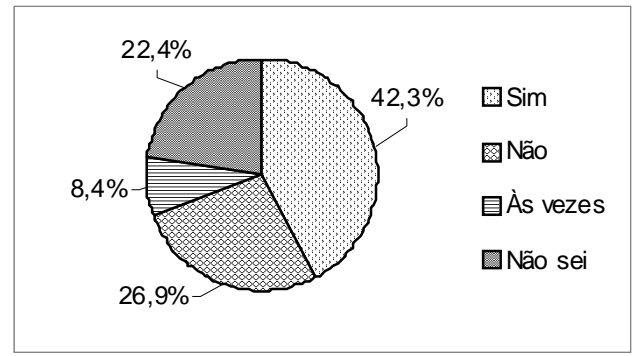

Figura 6. Percepção do consumidor quanto a raça ser garantia de qualidade da carne. (Consumer's perception of the breed be quality assurance of meat).

nunca haviam consumido o produto pesquisado. Boa parte da amostra pesquisada não acredita ou desconhece o fato que as raças britânicas apresentam carne de melhor qualidade do que as raças zebuínas ou continentais (Shackelford et al., 2011), talvez pelo pouco interesse em remunerar esses produtos, devNeste item foi abordada a uniformidade da percepção entre os agentes envolvidos no processo de produção e distribuição das carnes de marcas ligadas às raças (tabela VII). Os dados mostram alto coeficiente de variação nas respostas à questão 6, que argüia a respeito do consumo de produtos ligados aos selos de raças. Coeficientes de variação abaixo de $20 \%$ foram observados nas questões 1 e 4 , que argüiam quais fatores influenciam na decisão de compra dos consumidores e o quanto a mais vale uma carne com algum selo de qualidade. Esses resultados indicam que a cadeia de produção possui bom entendimento a respeito das preferências dos consumidores e a valorização que deve ter esse produto, embora nesta mesma pesquisa tenha se observado que o conhecimento sobre as certificações de carnes ligadas às raças bovinas é baixo (figura 5).

Estudando a comercialização de carne bovina na cidade de Porto Alegre, Teixeira (2013) constatou que o público jovem é um consumidor desinformado a respeito dos processos de certificação de carnes, dife- rente das pessoas com mais idade, maior renda e maior nível de instrução. Esse desconhecimento pode ser resultado de vários fatores combinados. O primeiro deles pode estar relacionado a um baixo investimento em publicidade e propaganda, o seguinte poderia ser uma agregação de preço demasiadamente elevada, inibindo os consumidores de provar as marcas de carne. $\mathrm{O}$ terceiro fator pode estar relacionado à satisfação que os consumidores encontram nas demais marcas de carne disponíveis no mercado.

Apenas na questão 3 , que arguia os agentes sobre a pessoa que poderia passar informação sobre qualidade da carne aos consumidores, foi observada uma resposta discrepante do gerente de compra de gado em relação aos demais agentes. Nas demais questões e entre os demais agentes, conforme já discutido na tabela VIII, se observa relativa uniformidade nas respostas às questões abordadas nesta pesquisa (figura 7). Não há dúvidas que a uniformidade de percepções entre os elos da cadeia de produção pode aumentar, mas em todas as questões se percebe grande parte dos agentes com entendimentos semelhantes aos consumidores finais, fato importante à medida que parte do consumidor a sinalização de qualidade de uma cadeia de produção.

No caso das marcas de carne usadas

Tabela VII. Percepção do consumidor (\%) quanto a raça ser garantia de qualidade da carne nas redes pesquisadas. (Consumer's perception (\%) of the breed be quality assurance of meat in networks surveyed).

\begin{tabular}{lcccc}
\hline Rede* $^{*}$ & Sim & Não & Às vezes & Não sei \\
\hline A & 45,2 & 28,6 & 7,1 & 19,0 \\
B & 33,3 & 30,8 & 10,0 & 25,8 \\
p $>\mathrm{X}^{2}$ & 0,08 & 0,91 & 0,51 & 0,35
\end{tabular}

*Rede A caracterizada por público com menor poder aquisito que a rede $B$. 
Tabela VIII. Uniformidade das respostas nas diferentes questões*. (Uniformity of answers in the different issues*).

\begin{tabular}{lcccccc}
\hline Agente da cadeia de produção & \multicolumn{7}{c}{ Questão** $^{*}$} \\
& 1 & 2 & 3 & 4 & 5 & 6 \\
Gerente & 4,33 & 2,33 & 3,00 & 3,00 & 2,67 & 1,00 \\
Nível Interm. & 3,33 & 3,33 & 3,33 & 2,83 & 1,83 & 2,33 \\
Açougueiro & 3,57 & 2,29 & 3,71 & 3,43 & 1,71 & 2,00 \\
Consumidor & 3,30 & 2,11 & 4,19 & 2,18 & 1,18 & 2,11 \\
Ger. Comercial & 5,00 & 2,00 & 4,00 & 4,00 & 2,00 & 1,00 \\
Ger. Compra Gado & 5,00 & 4,00 & 6,00 & 3,00 & 2,00 & 1,00 \\
Produtores & 4,00 & 3,60 & 3,00 & 3,40 & 2,40 & 1,20 \\
Média & 4,08 & 2,81 & 3,89 & 3,12 & 1,97 & 1,52 \\
Desvio-Padrão & 0,73 & 0,81 & 1,04 & 0,57 & 0,48 & 0,60 \\
Coeficiente de variação, \% & 17,89 & 28,94 & 26,71 & 18,22 & 24,31 & 39,39 \\
\hline
\end{tabular}

*As respostas dos questionários estruturados foram transformadas em números para que pudesse ser comparada a uniformidade de respostas e quantificado um desvio-padrão entre todos os agentes. ${ }^{* *}$ Questão: 1- Marque a importância de 1 a 5 dos fatores de maior influencia na hora da compra de carne?; 2- Quem pode dar informações sobre qualidade de carne pra você?; 3- Em ordem, quais são as informações mais importantes como indicadores de qualidade?; 4- Você acredita que vale uma carne com algum selo de qualidade vale mais? Quanto?; 5- Você consome alguma carne com o selo ligado a alguma raça? Qual(is)?; 6- Na sua opinião, a raça garante melhor qualidade à carne?

como referencial nesta pesquisa a questão parece estar restrita ao fato de uma parte representativa dos consumidores conhecerem, mas nunca terem provado os cortes oferecidos nas redes supermercadistas pesquisadas. Em seu trabalho Van Wezemael et al. (2012) afirmam que o fornecimento de informações confiáveis em encontro aos desejos dos consumidores é fundamental no desenvolvimento das cadeias produtivas da carne.

De qualquer forma, a diferenciação da carne bovina no Sul do Brasil é um processo recente e, sem dúvidas, o estabelecimento de um padrão de qualidade em determinadas marcas de carne serviu para balizar uma melhoria geral dos produtos comercializados sem uma marca específica, pois existe um referencial de qualidade exposto nas gôndolas. As mudanças socioeconômicas e demográficas que vêm ocorrendo no Brasil motivam estudos que apontem qual a satisfação do consumidor, pois dele depen- de o sucesso e desenvolvimento da cadeia. O conhecimento dos fatores que influenciam na compra de determinado produto ajuda a entender o consumidor (Vaz et al., 2013).

\section{CONCLUSÕES}

A análise sobre a qualidade percebida pelos consumidores de carnes bovinas de marcas, freqüentadores de duas redes de supermercados, mostrou pouca variação entre as populações.As marcas ligadas a raças reconhecidas por produzirem carnes bovinas de melhor qualidade gustativa possuem baixa valorização, em parte de pelo fato de boa parte dos consumidores não ter provado os produtos analisados. Também se observou que as questões de qualidade não estão bem claras aos consumidores, tendo em vista o alto percentual de pessoas que analisam a qualidade em função do aspecto do produto e pelas informações obtidas junto aos açougueiros. 


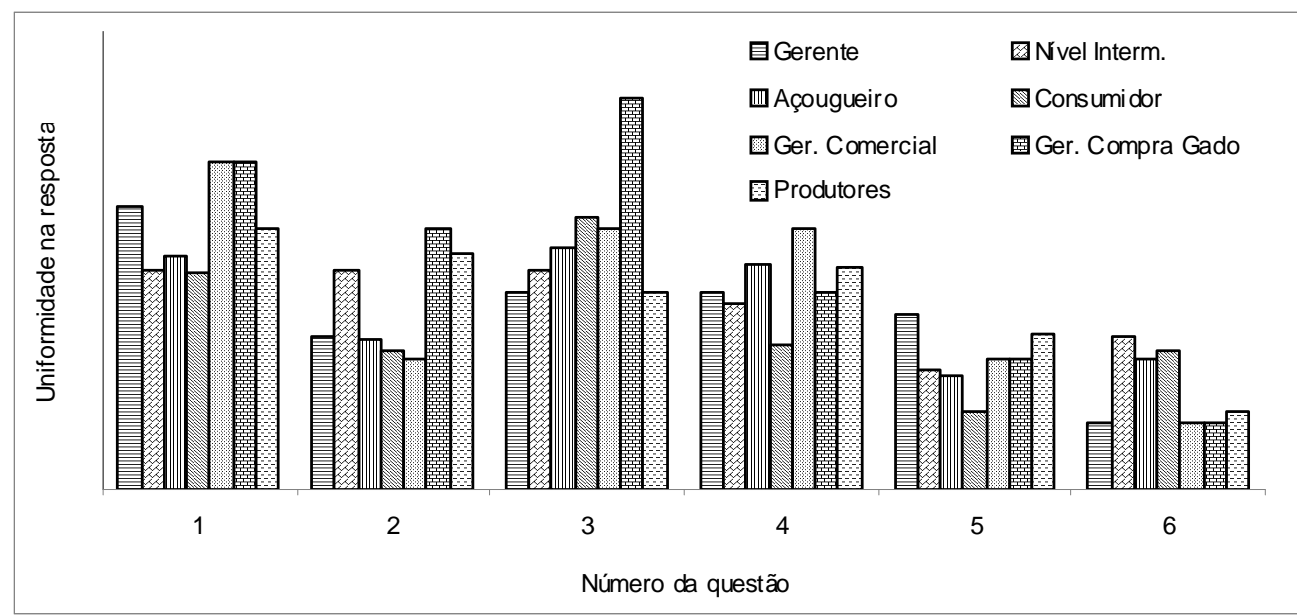

Questão: 1- Marque a importância de 1 a 5 dos fatores de maior influencia na hora da compra de carne?; 2- Quem pode dar informações sobre qualidade de carne pra você?; 3- Em ordem, quais são as informações mais importantes como indicadores de qualidade?; 4- Você acredita que vale uma carne com algum selo de qualidade vale mais? Quanto?; 5- Você consome alguma carne com o selo ligado a alguma raça? Qual(is)?; 6- Na sua opinião, a raça garante melhor qualidade à carne?

Figura 7. Percepção de qualidade entre os diferentes agentes da cadeia de produção. (Perception of quality among the different agents in the production chain).

As respostas acerca de qualidade da carne entre os sete diferentes agentes da cadeia de produção pesquisados foram relativamente uniformes indicando que a cadeia de produção possui entendimento similar a respeito das características rela-

\section{BIBLIOGRAFIA}

Angulo, A.M. and Gil, J.M. 2007. Risk perception and consumer willingness to pay for certified beef in Spain. Food Quality and Preference, 18: 1106-1117.

Barcellos, M.D.; Krystallis, A.; Saab, M.S.M.; Kügler, J.O. and Grunert, K.G. 2011. Investigating the gap between citizens' sustainability attitudes and food purchasing behaviour: empirical evidence from Brazilian pork consumers. Int $\mathrm{J}$ Consumer Studies, 35: 391-402.

Barcelos, M.D. e Callegaro, C.A.M. 2002. A importância da informação como indicador de qualidade: o caso da compra de carne bovina em Porto Alegre. Anais do ENANPAD. ANPAD. Salvador. cionadas a carne bovina. Esses resultados indicam aos gestores da cadeia de produção que a atual demanda pode estar restrita à limitação de renda da população ou à falta de informação decorrente do pouco investimento em publicidade e propaganda.

Barcellos, M.D. 2004. Informação e qualidade na compra de carne bovina. Revista de Administração FACES Journal, 3: 43-59.

Batalha, M.O. e Buainain, A.M. 2007. Cadeia produtiva de carne bovina. Série Agronegócios. MAPA, 8.

Brandão, F.S.; Ceolin, A.C.; Canozzi, M.E.A.; Révillion, J.F.P. e Barcellos, J.O.J. 2012. Confiança e agregação de valor em carnes com indicação geográfica. Arq Bras Med Vet Zootec, 64: 458-464.

Brisola, M.V. e Castro, A.M.G. 2005a. Preferências do consumidor de carne bovina do Distrito Federal pelo ponto de compra e pelo produto adquirido. Caderno de Pesquisas em Admi- 
nistração, 12: 81-99.

Brisola, M.V. e Castro, A.M.G. 2005b. Sintonia da informação sobre as preferências dos consumidores de carne bovina entre os agentes da cadeia de produção no Distrito Federal. Organizações Rurais e Agroindustriais, 7: 370-381.

Champredonde, M.; Vitrolles, D.; Casabianca, F. y Cerdan, C. 2014. La Pampa como indicación geográfica para diferenciar carnes vacunas en Argentina y en Brasil: motivaciones y limitantes. Agroalimentaria, 20: 35-52.

Grunert, K.G.; Bredahl, L. e Brunso, K. 2004. Consumer perception of meat quality and implications for product development in the meat sector: a review. Meat Sci, 66, 259-272.

Instituto Brasileiro de Geografia e Estatística IBGE. Censo 2010. www. ibge.com.br (16/09/ 2014).

Mazzuchetti, R.N. e Batalha, M.A. 2004. O comportamento do consumidor em relação ao consumo e às estruturas de comercialização da carne bovina na região de Amerios/PR. Rev Varia Sci, 4: 25-43.

Schlindwein, M.M. e Kassouf, A.L. Análise da influência de alguns fatores socioeconômicos e demográficos no consumo domiciliar de carnes no Brasil. Rev Econ Soc Rural, 44. doi.org/ 10.1590/S0103-20032006000300009 (25/08/ 2014).

Schnettler, B. y Sepúlveda, N. 2007. Márgenes de comercialización de la carne bovina en Chile. Rev Cient, 17: 606-613.

Shackelford, S.D.; Wheeler, T.L. and Koohmaraie, M. 2012. Validation of a model for online classification of US select beef carcasses for longissimus tenderness using visible and nearinfrared reflectance spectroscopy. J Anim Sci, 90: 973-977.

Souza, J.P. 1999. As estratégias competitivas da indústria brasileira de carnes: a ótica do distri- buidor. UFSC. Florianópolis.

Souki, G.Q., Salazar, G.T.; Antonialli, L.M. e Pereira, C.A. 2003. Atributos que afetam a decisão de compra dos consumidores de carne bovina. Organizações Rurais e Agroindustriais. Rev Administração, UFLA, 5: 36-51.

Teixeira, J.L. 2013. Perfil do consumidor de carne bovina em Porto Alegre, RS. Faculdade de Veterinária da UFRGS. Porto Alegre.

Van Wezemael, L.; Ueland, Ø.; Rødbotten, R.; Smet, S.; Scholderer, J. and Verbeke, W. 2012. The effect of technology information on consumer expectations and liking of beef. Meat Sci, 90: 444-450.

Vaz, F.N.; Dewes, H.; Padula, A.D. and Talamini, E. 2013. Meat market reaction towards mass media and science communication on bovine spongiform encephalopathy. J Sci Commun, 12. http://jcom.sissa.it/archive/12/02/JCOM1202 \%282013\%29A02/JCOM1202\%282013\% 29A02.pdf (25/08/2014).

Vaz, F.N.; Restle, J.; Pacheco, P.S.; Freitas, A.K.; Peixoto, L.A.O. e Carrilho, C.O. 2002. Características de carcaça e da carne de novilhos superprecoces de três grupos genéticos, gerados por fêmeas de dois anos. Rev Bras Zootecn, 31: 1973-1982.

Velho, J.P.; Barcellos, J.O.J.; Lengler, L.; Elias, S.A.A. e Oliveira, T.E. 2009. Disposição dos consumidores porto-alegrenses à compra de carne bovina com certificação. Rev Bras Zootecn, 38: 399-404.

Verbeke, W.; Rutsaert, P.; Bonne, K. and Vermeir, I. 2013. Credence quality coordination and consumers' willingness-to-pay for certified Halal labelled meat. Meat Sci, 95: 790-797.

Zylbersztajn, D. 2000. Conceitos gerais, evolução e apresentação do sistema agroindustrial. In: Zylbersztajn, D.; Neves, M. F. (Orgs.). Economia e gestão dos negócios agroalimentares. Pioneira. São Paulo.

Archivos de zootecnia vol. 63, num. 244, p. 644. 